\title{
Atrial Myxoma Saddle Aortic Embolism: An Overview
}

\author{
Huthayfa Ghanem*1, Sami Asfar ${ }^{2}$, Marzouk Albader ${ }^{3}$, Jassim Al-Ali ${ }^{3}$ and Ibrahim Hanbal ${ }^{4}$ \\ ${ }^{1}$ Senior Vascular Fellow, Bedford Hospital NHS Trust, UK \\ ${ }^{2}$ Professor of Surgery and Senior Consultant Vascular and Hepatic Surgeon, Kuwait University Health Sciences Center, Kuwait \\ ${ }^{3}$ Consultant Vascular Surgeon, Mubarak Al-Kabeer Hospital, Kuwait \\ ${ }^{4}$ Professor of Vascular Surgery, Al-Azhar Faculty of Medicine, Egypt
}

*Corresponding author: Huthayfa Ghanem, Senior Vascular Fellow, Bedford Hospital

NHS Trust, UK.

\author{
Received Date: July 02, 2019 \\ Published Date: July 05, 2019
}

\begin{abstract}
Although they are rare, atrial myxomas are the most common primary cardiac tumours, to be followed by sarcomas. These tumours are benign and don't metastasize; however, they do embolize. Myxoma emboli usually go into the systemic circulation because of their usual location in the left atrium. Early diagnosis is usually challenging because of the non-specific symptoms. Therefore, it is not uncommon to have them presented with embolism, congestive heart failure or sudden cardiac death. Vascular surgeons are usually exposed to those tumours when the affected patients come to A/E department with acutely ischaemic limb(s) and / or strokes. Only after initial imaging and /or embolectomy, myxoma might be considered as a possible culprit. Once suspected, further detailed cardiac imaging must be done urgently to confirm the diagnosis in order to proceed with tumour resection at the earliest, considering myxoma tumour propensity for recurrent and multiple embolization with the subsequent high risk of morbidity and mortality. Hence, a high index of suspicion, early diagnosis and excision of these masses are vital to avoid the adverse clinical outcome, taking into account the excellent prognosis after resection [1-4].
\end{abstract}

Keywords: Left Atrium; Myxoma; Myxomectomy; Saddle Embolus; Acute Limb Ischaemia

\section{Introduction}

In 1952, myxoma was first diagnosed by Goldberg [5]. These tumours account for up to $50 \%$ of primary cardiac tumours. Around $80 \%$ of them occur in the left atrium, usually at the border of fossa ovalis in the interatrial septum. The estimated incidence is 0.5 per million population per year, and the incidence at autopsy is $0.02 \%$. Most of these tumours are sporadic. Nonetheless, $10 \%$ of myxomas have an autosomal dominant inheritance such in the case of Carney syndrome.

Myxomas can occur at any age; however, they are most commonly seen between the third and sixth decade, and the mean age of presentation was 56 in sporadic cases, 25 in familial cases and 37.1 overall. There is female preponderance of 2-3:1 [6-9].

The most common symptom is dyspnoea (75\%). Constitutional symptoms due to IL-6 production by the tumour such as arthralgia, fatigue, cyanosis, clubbing, weight loss, rashes and Raynaud's phenomenon occur in $50 \%$, dizziness and syncope occur in $20 \%$, and haemoptysis in up to $15 \%$ of patients. Only in around $20 \%$ of cases, myxomas can be asymptomatic or discovered incidentally [7, 8].
More than $50 \%$ of the patients with left atrial myxoma have clinical evidence of mitral valve dysfunction, with systolic and diastolic murmurs on auscultation. Large left atrial tumours produce diastolic sound "tumor plop" because of obstruction to ventricular in-flow (mechanical interference). In some patients, these tumours can cause arrhythmias $[10,11]$.

Features of embolism can be seen in any vascular bed in up to $40 \%$ of myxomas, commonly affecting arteries of CNS (50\% of embolic events) and retinae. Furthermore, $10 \%$ of coronary embolic events are thought to be due to myxomas. Right sided myxomas can embolize to pulmonary arteries or cause trans-septal paradoxical embolism [12,13].

The embolus can be: [14]

a) A fragment of the tumour

b) The whole tumour

c) An associated thrombus attached to the tumour (difficult to disagnose) 
d) Tumour (tumour part) and the attached thrombus (most common)

\section{The following features are associated with higher embolism potentials: [15-18]}

1. Size: $4.5 \mathrm{~cm}$ or less (more aggressive tumours with IL-6 production)

2. Shape: polypoid multilobed villous tumours

3. Consistency: $35 \%$ of myxomas are soft and friable

4. Location: left atrial and aortic valve tumours

5. Mobility: intermittently prolapsing masses

6. Growth rate: higher growth rates are associated with greater embolic likelihood (The reported growth rates vary from no growth, to between 1.3 to $6.9 \mathrm{~mm} / \mathrm{month})$. Growth rates are usually faster in recurrent cases.

7. Embolized tumours will usually embolize again concurrently.

8. Function: IL-6 production

9. Symptoms: less symptomatology is associated with higher risk

10. Associated atrial tachyarrhythmias

11. Mitral valve destruction

12. High platelets count and mean platelets volume

13. Associated thrombophilia

Morphologically, myxomas appear as yellowish, glistening, gelatinous, polypoid, smooth, lobulated or villiform, sessile or pedunculated masses usually $5-6 \mathrm{~cm}$ in diameter and, with a short stalk. Sometimes, the tumour can be large and mobile enough to cause valve obstruction [14] Figure 1. Microscopically, they show loose myxoid stroma containing proteoglycans. Polygonal stellate cells are found within the matrix, singly or in small clusters [14].

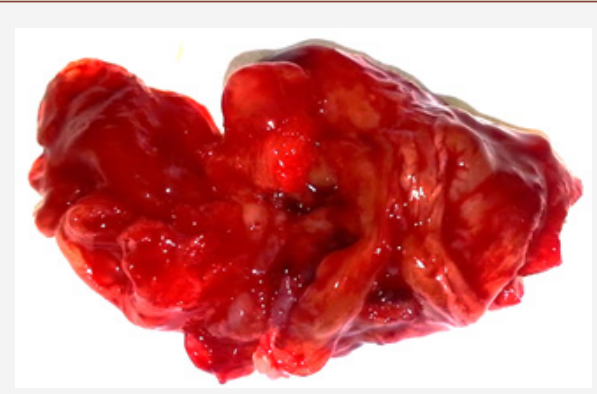

Figure 1: Left atrial myxoma embolus at aortic bifurcation retrieved during bilateral femoral embolectomy.

\section{Saddle Aortic Embolism}

Cardiac myxomata saddle aortic embolism was first described by Brewin (1951), Edwards and Johnson (1959) and Barham Carter et. al. (1960). In those early reports, they described the embolectomy procedures for acute limb ischaemia where the emboli were "jelly-like". Unfortunately, those patients died postoperatively and the post-mortem dissections revealed cardiac masses with consistencies similar to those obtained from lower limb surgeries [19] Figure 2. Only 1.5\% of peripheral embolism occurs due to cardiac tumors. Myxomas account for up to $40 \%$ of tumour embolism $[9,20]$.

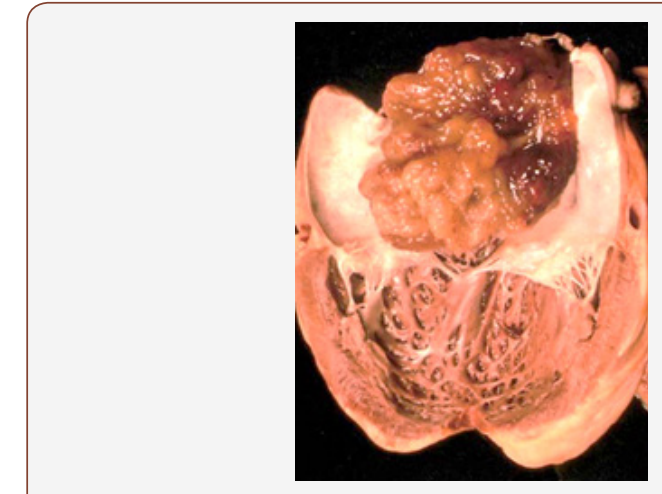

Figure 2: Post-mortum specimen showing the left atrium contains a large, polypoid tumour that protrude into the mitral valve orifice (from Rubin's pathology: clinicopathologic foundation of medicine $6^{\text {th }}$ edition, page: 532 ).

\section{Five Cases with Cardiac Myxoma Saddle Aortic} Embolism

Over a period of 10 years (2007-2017), 5 of the patients with acute bilateral lower limb ischaemia presented to Mubarak AlKabeer Hospital found to have left atrial myxoma saddle aortic embolism. All were otherwise healthy females and the mean age was 41.4 years $(37-59)$. The average duration of symptoms to presentation in A/E department was 5.2 hours $(4-11)$. Atrial myxomas were diagnosed by post-embolectomy echo scan in 3 and by histology in all patients. The left atrial myxoma residual average diameter was $3.7 \mathrm{~cm}$. All the 3 ladies with left atrial myxomas had excision after an average duration of 9 hours post embolectomy (6 15). Histology confirmed myxoma cardiac residuals in all examined masses. Post-operative period was uneventful in all patients. No recurrences detected with at least 2-year follow up duration.

During the same period, a total of 104 saddle aortic embolisms operations were performed, and the average duration of symptoms was 7.1 hours $(2-19)$.

Therefore, cardiac myxoma saddle aortic embolism accounted for $4.8 \%$ of all saddle aortic embolism (less than $0.3 \%$ in peripheral embolism). In addition, those patients tend to present earlier than other saddle aortic embolism patients.

According to our experience, the typical patient is:

a. Young female

b. Previously healthy (no arteriopathy, no atrial fibrillation)

Often, presents with multiple organ embolism. Less frequently, symptomatic myxomas presents with embolic events.

Acute ischaemia due to cardiac myxomata saddle embolism is usually severe (Rutherford stage II: limb threatening ischaemia). Embolus volume is usually higher in myxomas than other forms of embolism. The typical clinical scenario is a patient with the abovementioned characteristics comes to A/E department with features 
of acute bilateral lower limb ischaemia after only a few hours of onset of symptoms (earlier than with other causes of acute limb ischaemia) due to profound symptoms and massive embolism. Classically, those patients will have bilateral femoral embolectomy after an intravenous bolus of heparin directly without having preoperative scans. Intra-operatively, the retrieval of yellowish jelly like material should be alarming enough to justify arrangements for an echocardiography (preferably trans-oesophageal) in the immediate post-operative period (bedside). Once confirmed, prompt cardiac surgery input is mandatory to clear the cardiac residuals as soon as possible. Otherwise, the new embolism risk is exceedingly high and is usually fatal. It is not uncommon to have unremarkable echo scans after embolectomy due to embolization of the whole tumour; hence, tissue diagnosis will be the only way to confirm the diagnosis. Moreover, in such cases it is highly advisable to arrange for regular echo scans (possibly biannually) as the risk of having tumour cells left at myxoma bed in fossa ovalis cannot be omitted.

Cardiac myxomectomy for sporadic tumours is usually curative. Tumour manipulation should be done only after cardioplegia as the risk of fragmentation and embolism is usually there. Tumour excision along with its stalk and septal bed is recommended with pericardial patch septoplasty. Inspection of all champers is necessary as well as the repair of the damaged valves [21].

Surgical risks:
a. Early mortality: $2 \%$
b. Post-operative AF: $30 \%$
c. Neurologic complications: $3 \%$
d. Re-exploration: 5\% and usually due to bleeding [21].

Recurrences (up to $5 \%$ in sporadic tumors and more than $20 \%$ in familial cases and is uncommon after 5 years) are usually occurred due to:

\section{a. Incomplete excision}

b. $\quad$ Other foci

c. Implantation of tumour cells (intra- or extracardiac) [22].

There is no current guidelines or recommendations exist regarding the treatment of embolic manifestations; however, anticoagulation is recommended if associated with:

$-\mathrm{AF}$

- Some cases of dysrhythmia or valve destruction [23].

\section{Conclusion}

The incidence of atrial myxoma in saddle aortic embolism cases seems to be higher than its incidence in peripheral embolism in general. In other words, atrial myxoma embolism to the lower limbs is usually of the saddle type. This condition has to be considered in "typical patients" presented to A/E department with acute bilateral lower limb ischaemia, as the prompt diagnosis and timely intervention will significantly improve the clinical outcome.

\section{Acknowledgement}

None.

\section{Conflict of Interest}

No conflict of interest.

\section{References}

1. Obrenović-Kirćanski B, Mikić A, Parapid B, Djukić P, Kanjuh V, et al. (2013) A 30-year-single-center experience in atrial myxomas: from presentation to treatment and prognosis. Thorac Cardiovasc Surg 61(6): 530-536.

2. Baikoussis NG, Papakonstantinou NA, Dedeilias P, Argiriou M, Apostolakis E, et al. (2015) Cardiac tumors: a retrospective multicenter institutional study. J BUON 20(4): 1115-1123.

3. Patil NP, Dutta N, Satyarthy S, Geelani MA, Kumar Satsangi D, et al. (2011) Cardiac myxomas: experience over one decade. J Card Surg 26(4): 355-359.

4. Sungyong Hong, Kyun-Taek Park, Hyunmin Choe (2012) Total Occlusion of the Abdominal Aorta Caused by Detachment of Cardiac Myxoma. Korean J Thorac Cardiovasc Surg 45(3): 183-185.

5. Henry P Goldberg, Frank Glenn, Charles T Dotter, Israel Steinberg (1952) Myxoma of the Left Atrium: Diagnosis Made during Life with Operative and Postmortem Findings. Circulation 6(5): 727-726.

6. Larsson S, Lepore V, Kennergren C (1989) Atrial myxomas: results of 25 years' experience and review of the literature. Surgery 105(6): 695-698.

7. Pinede L, Duhaut P, Loire R (2001) Clinical presentation of left atrial cardiac myxoma. A series of 112 consecutive cases. Medicine (Baltimore) 80(3): 159-172.

8. Aggarwal SK, Barik R, Sarma TC, Iyer VR, Sai V, et al. (2007) Clinical presentation and investigation findings in cardiac myxomas: new insights from the developing world. Am Heart J 154(6): 1102-1107.

9. Mac Gowan SW, Sidhu P, Aherne T, Luke D, Wood AE, et al. (1983) Atrial myxoma: national incidence, diagnosis and surgical management. Ir J Med Sci 162(6): 223-226.

10. Ho VB, Jeffrey MJ, Hirsch MC (2006) Left Atrial Myxoma. Milit Med 171(9): iv-vi.

11. Wilson J (2011) Heart sounds podcast series. Texas Heart Institute.

12. Lee VH, Connolly HM, Brown RD (2007) Central nervous system manifestations of cardiac myxoma. Arch Neurol 64(8): 1115-1120.

13. Rios RE, Burmeister DB, Bean EW (2016) Complications of atrial myxoma. Am J Emerg Med 34 (12): 2465.e1-2465.e2.

14. Rubin Raphael, Strayer David (2012) Rubin's Pathology: Clinicopathologic Foundation of Medicine. Philadelphia, Pennsylvania: Lippincott Williams \& Wilkins Pp. 532.

15. Deng-ke He, Yu-feng Zhang, Yin Liang, Shi-xing Ye, Chong Wang, et al. (2015) Risk Factors for Embolism in Cardiac Myxoma: A Retrospective Analysis. Med Sci Monit 21: 1146-1154.

16. Zhengjun Wang, Shiqiao Chen, Mei Zhu, Wenlong Zhang, Haizhou Zhang, et al. (2016) Risk prediction for emboli and recurrence of primary cardiac myxomas after resection. Journal of Cardiothoracic Surgery 11: 22.

17. Mendoz CE, Rosado MF, Bernal L (2001) The Role of Interleukin-6 in Cases of Cardiac Myxoma: Clinical Features, Immunologic Abnormalities, and a Possible Role in Recurrence. Tex Heart Inst J 28(1): 3-7.

18. Andrew W ElBardissi, Joseph A Dearani, Richard C Daly, Charles J Mullany, Thomas A Orszulak, et al. (2009) Embolic Potential of Cardiac Tumors and Outcome After Resection A Case-Control Study. Stroke 40: $156-162$.

19. Carter Ab, Lowe Kg, Hill Ig (1960) Cardiac Myxomata And Aortic Saddle Embolism. Br Heart J 22(4): 502-504. 
20. Boutayeb A, Mahfoudi L, Moughil S (2017) Atrial Myxoma: From Diagnosis to Management. Clin Surg 2: 1498.

21. Shah IK, Dearani JA, Daly RC, Suri RM, Park SJ, et al. (2015) Cardiac myxomas: a 50-year experience with resection and analysis of risk factors for recurrence. Ann Thorac Surg 100(2): 495-500.

22. Sheng WB, Luo BE, Liu Y, Zhang H, Zou LJ, et al. (2012) Risk factors for postoperative recurrence of cardiac myxoma and the clinical managements: a report of 5 cases in one center and review of literature. Chin Med J (Engl) 125(16): 2914-2918.

23. Shavit L, Appelbaum L, Grenader T (2007) Atrial myxoma presenting with total occlusion of the abdominal aorta and multiple peripheral embolism. Eur J Intern Med 18(1): 74-75. 